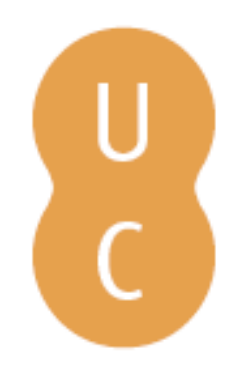

\title{
pombalina
}

\section{Mapeamento de riscos nas bacias hidrográficas de Caraguatatuba - SP}

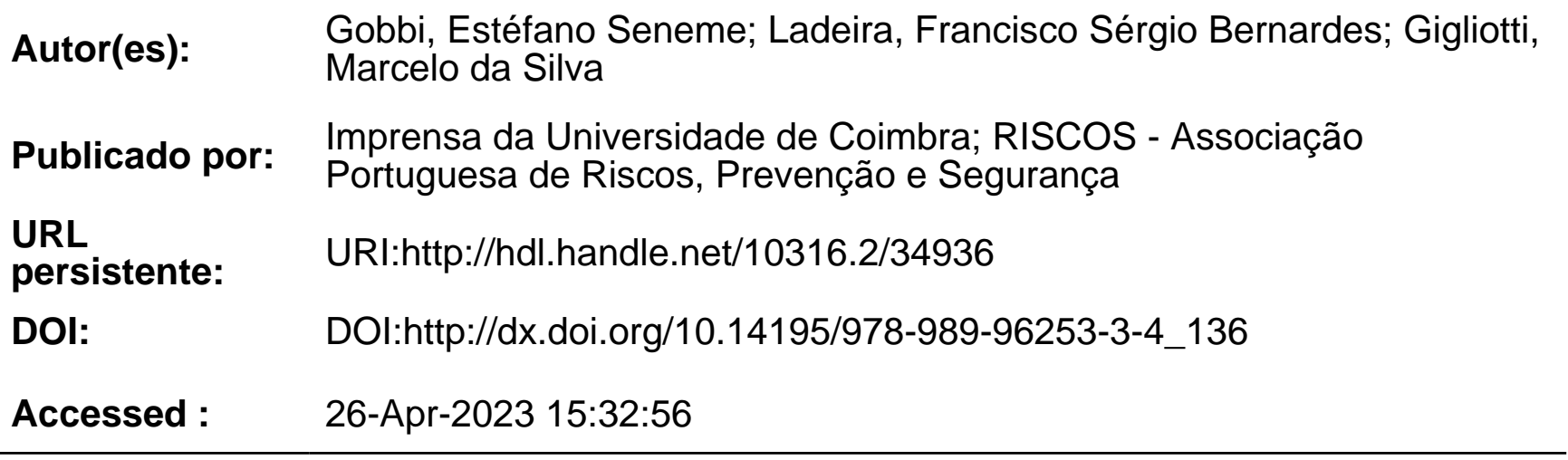

A navegação consulta e descarregamento dos títulos inseridos nas Bibliotecas Digitais UC Digitalis, UC Pombalina e UC Impactum, pressupõem a aceitação plena e sem reservas dos Termos e Condições de Uso destas Bibliotecas Digitais, disponíveis em https://digitalis.uc.pt/pt-pt/termos.

Conforme exposto nos referidos Termos e Condições de Uso, o descarregamento de títulos de acesso restrito requer uma licença válida de autorização devendo o utilizador aceder ao(s) documento(s) a partir de um endereço de IP da instituição detentora da supramencionada licença.

Ao utilizador é apenas permitido o descarregamento para uso pessoal, pelo que o emprego do(s) título(s) descarregado(s) para outro fim, designadamente comercial, carece de autorização do respetivo autor ou editor da obra.

Na medida em que todas as obras da UC Digitalis se encontram protegidas pelo Código do Direito de Autor e Direitos Conexos e demais legislação aplicável, toda a cópia, parcial ou total, deste documento, nos casos em que é legalmente admitida, deverá conter ou fazer-se acompanhar por este aviso.

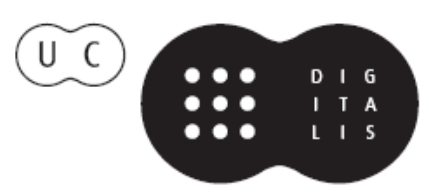



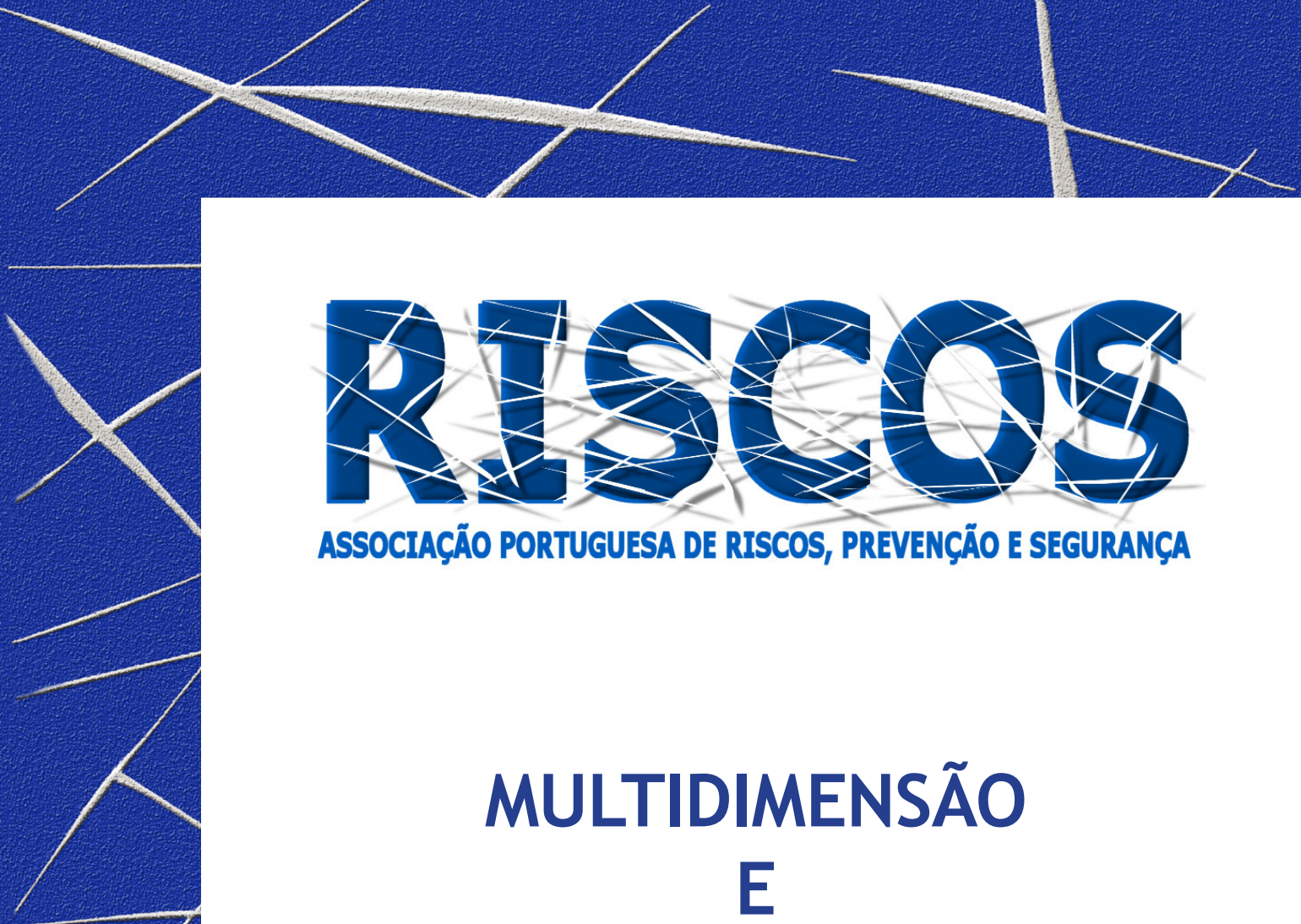

ASSOCIAÇÃO PORTUGUESA DE RISCOS, PREVENCCÃO E SEGURANÇA

MULTIDIMENSÃO

E
TERRITÓRIOS DE RISCO

III Congresso Internacional

I Simpósio Ibero-Americano

VIII Encontro Nacional de Riscos

Guimarães

2014 


\title{
MAPEAMENTO DE RISCOS NAS BACIAS HIDROGRÁFICAS DE CARAGUATATUBA-SP
}

\author{
Estéfano Seneme Gobbi \\ Faculdade de Geografia, Pontifícia Universidade Católica de Campinas, Brasil \\ estefano.gobbi@puc-campinas.edu.br \\ Francisco Sérgio Bernardes Ladeira \\ Universidade Estadual de Campinas, Brasil \\ fsbladeira@ige.unicamp.br \\ Marcelo da Silva Gigliotti \\ Universidade Estadual de Campinas marcelo.gigliotti@ige.unicamp.br
}

\begin{abstract}
RESUMO
O intenso intemperismo verificado nas escarpas da Serra do Mar promove um grande desenvolvimento de material pedogenético que, associado a elevadas declividades e precipitações temporalmente concentradas são os principais fatores que desencadeiam movimentos de massa e depósitos gravitacionais na Planície Costeira de Caraguatatuba-SP e em tantas outras áreas do litoral brasileiro. Esses movimentos de massa orientam-se preferencialmente pelos canais de drenagem, que também concentram os maiores riscos no que concerne a corridas de lama, rolamento de blocos e inundações.

Movimentos de massa são processos inerentes à Serra do Mar e fazem parte da dinâmica natural das faixas litorâneas próximas ao Planalto Atlântico. As zonas de contato entre a Planície Costeira e as escarpas da Serra do Mar são áreas de suscetibilidade maior a esses desastres naturais, de maneira que sua ocupação deveria ser restringida, evitando assim a maior vulnerabilidade socioeconômica das pessoas e atividades que são verificadas nessas áreas. Entretanto, historicamente é na faixa litorânea que se concentra um grande contingente populacional e se desenvolve grande parte das atividades econômicas.
\end{abstract}

Palavras-chave: Mapeamento de Riscos, Planície Costeira, Escorregamento de Massa.

\section{Introdução}

A Planície sedimentar de Caraguatatuba é drenada em sua maior área pelo Rio Juqueriquerê (formado pelos rios Claro, Piraçununga e Camburu), e na porção setentrional pelos rios Santo Antônio, Lagoa e Guaxinduba, além de pequenos leitos d'água que correm diretamente ao oceano. Grande parte do aporte sedimentar aluvial que chega a planície se deve a área ainda menos antropizada do município (região SO), carreado pelos leitos do Claro, do Piraçununga e do Camburu (CRUZ, 1974).

Entretanto, as áreas mais ocupadas da Planície concentram-se nas bacias dos Rios Santo Antônio, Rio do Ouro, Ribeirão da Lagoa e Rio Guaxinduba, de maneira que eventos de escorregamento de massa como o ocorrido em 1967 sejam mais impactantes socioeconomicamente nessas áreas.

Em atividades de campo foram verificadas as áreas de contato entre a Planície Sedimentar e a Serra do Mar que, somadas aos dados altimétricos do Plano Cartográfico do Estado de São Paulo (1978) e às coletas de material pedológico por meio de tradagens (trado holandês) embasaram o delimitação das áreas de maior suscetibilidade a riscos associados a depósitos de movimentos de massa e inundações em ambiente SIG.

\section{Caracterização da Área}

APlanície Sedimentar de Caraguatatuba é drenada por quatro bacias hidrográficas (Juqueriquerê, Guaximduba, Santo Antônio e Lagoa), além de pequenos cursos d’água que deságuam diretamente no Oceano Atlântico, como visualizado na Figura 1. 


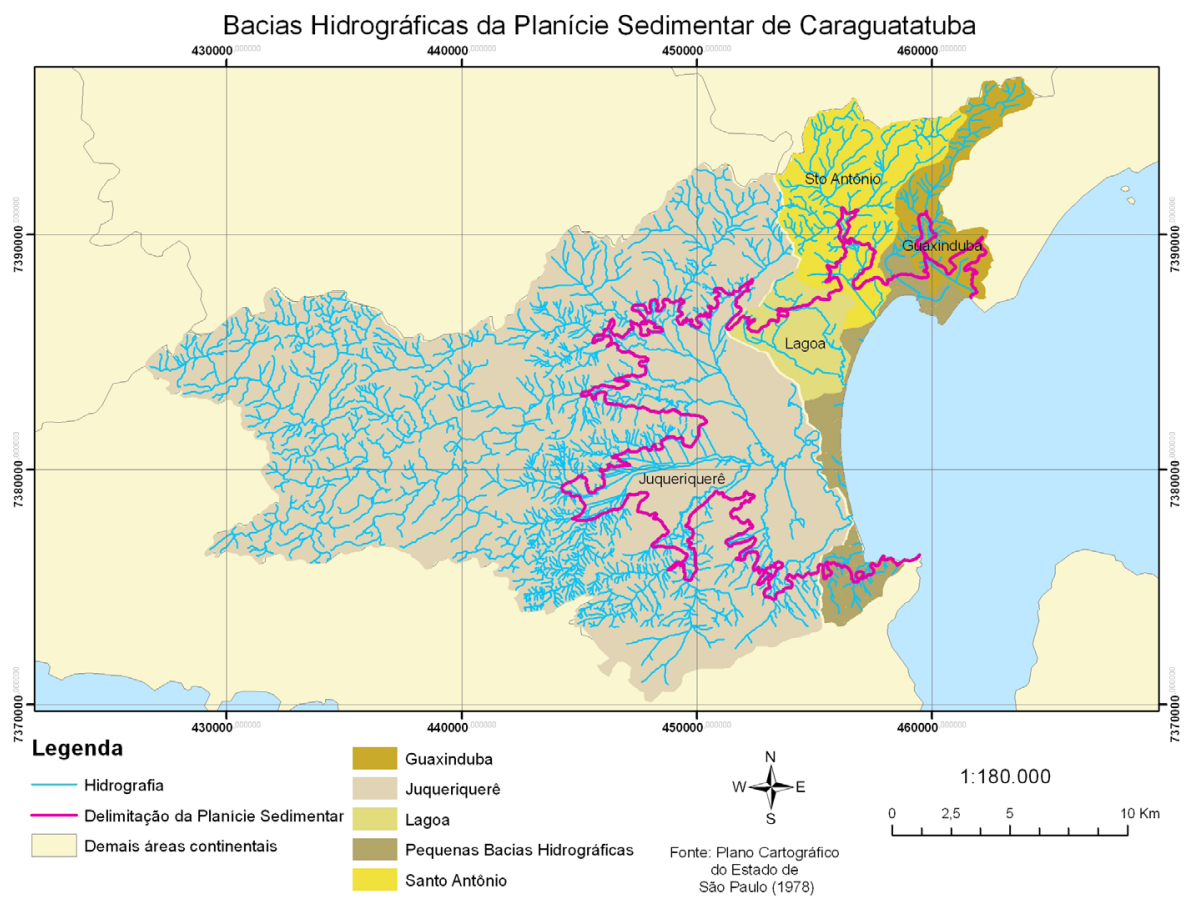

Figura 1 - Bacias Hidrográficas da Planicie Sedimentar de Caraguatatuba

O Rio Guaxinduba é responsável pela drenagem de uma pequena área da Planície, constituindo uma das menores bacias hidrográficas de Caraguatatuba. Caracteriza-se por apresentar um vale de alvéolo interno já rebaixado, com cotas muito próximas as do nível do mar, percorrendo seu traçado em meio a formações arenosas originadas de depósitos marinhos e de seus próprios depósitos aluviais, já que se seu curso na planície não tivesse sido retificado para a praia Martim de Sá, deveria provavelmente apresentar um padrão anastomosado. Segundo Freitas (1959), as modificações climáticas ocorridas no quaternário propiciaram que a zona de contato entre a planície e as encostas da serra primeiramente sofressem um intenso intemperismo que posteriormente possibilitou a formação de largos alvéolos, caracterizando o padrão de drenagem atual do rio. O interflúvio com a bacia do Rio Santo Antônio é caracterizado antes de atingir a Planície, por cotas de 429 a 502, na forma de "rocha exposta em dente canino", como trás Cruz (1974).

O Rio Juqueriquerê é formado na confluência do Rio Claro, Rio Perequê e Rio Tinga ou Camburu, ainda apresentando como importantes afluentes o Rio Perequê-Mirim, o Rio São Tomé, o Rio Piraçununga, o Ribeirão Pau-d'álho e o Córrego Canivetal (PLANO CARTOGRÁFICO DO ESTADO DE SÃO PAULO, 1978). As áreas dos leitos dos rios limítrofes entre as maiores declividades das escarpas do cristalino e a grande planura da Planície Sedimentar traduzem-se em locais entulhados por blocos rolados ou carreados por forças fluviais/gravitacionais, de modo a se depositarem nestas áreas de contato e demarcando o inicio de um canal anastomosado e meandrante. Devem ser consideradas as hipóteses de evolução de dinâmica de deposição de 
acordo com a evolução da drenagem, pois com a variação do nível do mar e a consequente mudança do nível de base, a e erosão e a sedimentação fluvial tem seus padrões modificados. De acordo com Tesslet et al (2006), a área drenada pelos Rios santo Antõnio e Lagoa são naturalmente propensas a deposição de sedimentos, por conta da deriva sedimentar longitudinal, que se enfraquece e tende a depositar-se neste segmento costeiro.

Em consequência de chuvas torrenciais na região, em março de 1967, foram verificados um grande número de ocorrências de corridas de lama, porém de acordo com Petri \& Suguio (1971) a montante predomina a ocorrência de matacões, enquanto que a jusante, são verificados seixos e areias, que tem sua granulometria reduzida a medida que o rio se aproxima do Atlântico. Este fato é explicado por Suguio (1980) pelo Santo Antônio possuir um canal anastomosado, de modo a ter sua energia de transporte reduzida abruptamente ao atingir a planície sedimentar.

Ainda sobre aquele evento, Cruz (1974) trás que o vale do leito principal que era da ordem de 10 a 20 metros passou a ter a largura de 60 a 80 metros depois da série de escorregamentos de 1967. A autora ainda trás que o interflúvio do rio já nas cotas menos elevadas da Serra Mar apresenta cotas de altitudes variáveis entre 200 e 250 metros.

O Rio Santo Antônio após recebem um imenso aporte sedimentar em um único evento e terem seus vales entulhados passaram a buscar um novo entalhe para seu talvegue, buscando desviar o curso dos novos taludes de detritos que ocupavam a área de suas bacias.

\section{Resultados e Discussão}

Ao serem realizadas tradagens e análises de solo nas áreas de contato das escarpas cristalinas da Serra do Mar e a Planície Sedimentar de Caraguatatuba foram verificadas evidências de escorregamentos de massa pretérito, assim com a presença de blocos rolados. Estas informações de campo, somadas às referencias bibliográficas (Cruz, 1974; Gobbi, 2009; Gobbi \& Ladeira, 2011 e Petri \& Suguio, 1971) foram fundamentais para e confecção do Mapa de Riscos associados a Planície Sedimentar de Caraguatatuba (Figura 2). Há de se destacar também que, apesar de não serem encontradas evidências de Corridas de Lama nas atividades de campo, Cruz (1974) afirma que nos eventos de 1967 esse risco foi bastante intenso e verificado principalmente nas atuais áreas centrais do município (Bacia do Rio Santo Antônio). Desta forma, este risco, associado a configuração da drenagem também será contemplado.

Ao analisar as declividades para a área, nota-se que este fator é preponderante para a ocorrência dos escorregamentos de massa e que sua mudança apresenta-se de maneira gradual entre os 10 e 20 metros de altitude. A partir desta cota, a declividade verificada é bastante íngreme, de maneira a determinar que as altitudes superiores sejam áreas deflagradoras da movimentação de massa e as áreas limítrofes da Planície com as escarpas (cotas inferiores a 20 metros) estão mais suscetíveis a ocorrência de eventos associados a deposição dos escorregamentos de massa, assim como visualizado na Figura 2. A declividade acaba por influenciar também na formação do solo, pois modifica a dinâmica da água nos perfis de solo, alterando a pedogênese.

Para o risco de rolamento de blocos, a delimitação da área de riscos está associada, além do fator declividade, à hidrografia, pois esta tende a limitar o deslocamento dos matacões, que, ao atingirem o leito d'água, perdem a energia cinética da ação gravitacional e tendem a entulhar o canal (como demonstra a Figura 3), pois a energia fluvial dos rios na planície não são suficientes para a mobilização deste volume de material. 


\section{Mapa de Riscos associados a Planície Sedimentar de Caraguatatuba}

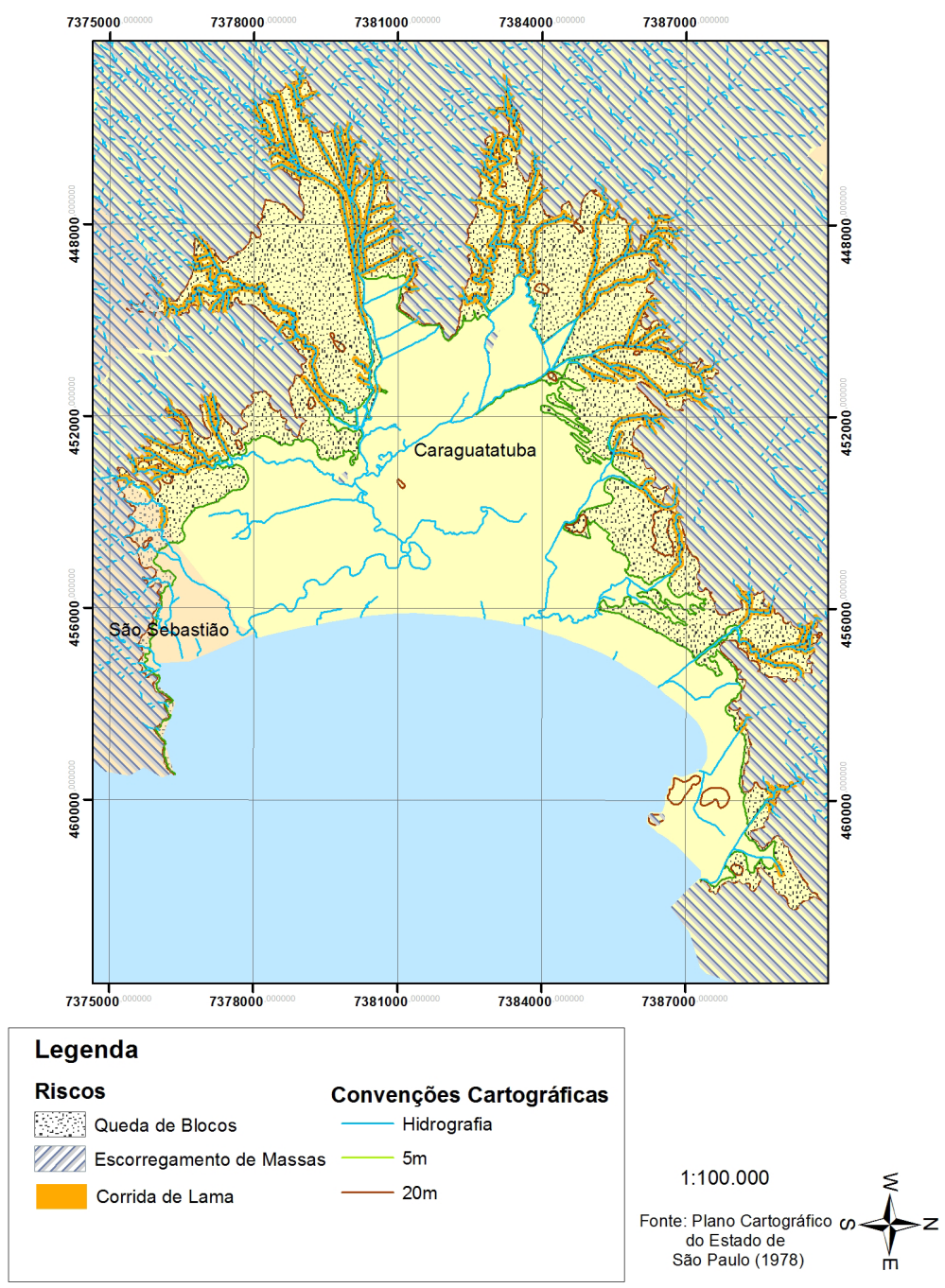

Figura 2 Mapa de Riscos associados a Planície Sedimentar de Caraguatatuba

\section{Considerações Finais}

A delimitação da Planície apresentou como fundamental não para a determinação da área de estudos, como também para a verificação dos locais de maior concentração das atividades antrópicas e suas respectivas vulnerabilidades aos riscos do limite das escarpas com a planície. Esta delimitação deve-se a declividade verificada nessas áreas, já que à partir da altitude de 20 metros o terreno apresenta uma maior inclinação e demonstra-se mais susceptível a mobilização. Desta forma, as áreas mais próximas às cotas de 20 metros de altitude, assim como de maior 
proximidade com cursos d'água apresentam-se de maior risco a sua ocupação, devendo ser evitadas para a construção de moradias e atividades comerciais.

\section{Agradecimentos}

Os autores agradecem a Fundação de Amparo à Pesquisa do Estado de São Paulo (FAPESP07/53644-1) pelo financiamento da pesquisa, ao projeto "Estudos da previsibilidade de eventos meteorológicos extremos na Serra do Mar” (FAPESP-04/09469-0).

\section{Bibliografia}

CRUZ, O. A Serra do Mar e o litoral na Área de Caraguatatuba-SP: Contribuição a Geomorfologia Litorânea Tropical. Tese de Doutorado (Doutorado em Geografia). FFLCH - USP. São Paulo-SP. 1974.

FREITAS, R. O. Roteiro da $5^{\text {a }}$ excursão: litoral norte do estado de São Paulo - Ilhabela a Ubatuba. In: $13^{\circ}$ Congresso de Geologia de São Paulo. 1959. p. 24.

GOBBI, E. S. Depósitos gravitacionais, marinhos e fluviais e a evolução geomorfológica da planície sedimentar de Caraguaratuba-SP. Dissertação (Mestrado em Geografia). Instituto de Geociências. Universidade Estadual de Campinas. Campinas-SP. 2009.

GOBBI, E. S., LADEIRA, F. S. B. Proposta para mapeamento de riscos associados a movimentos de massa e inundação: o caso de Ubatuba, SP. In Revista Geociências, v. 30 n 3. p.445-456. São Paulo-SP. 2011.

PETRI, S. \& SUGUIO, K. Características granulométricas dos escorregamentos de Caraguatatuba, São Paulo, como subsídio para o estudo da sedimentação neocenozóica do sudeste brasileiro. In: Congresso Brasileiro de Geologia (25). São Paulo-SP. 1971. p.71-82.

PLANO CARTOGRÁFICO DO ESTADO DE SÃO PAULO - Escala 1:10.000. 1978.

SUGUIO, K. Ambientes de Sedimentação e fácies sedimentares. In: Rochas Sedimentares: propriedades, gênese, importância econômica. São Paulo-SP. 1980. Edgar Blücher. p. 305-389.

TESSLER, M. G., GOYA, S. C., YOSHIKAWA, P.S., HURTADO, S. N. Erosão e Progradação do Litoral do Estado de São Paulo. In MUEHE, D. (org) Erosão e Progradação do Litoral Brasileiro. $1^{\text {a }}$ ed. Brasília-DF: Ministério do Meio Ambiente, 2006. p. 297-346. 